\title{
The magnitude and Associated Factors of Pneumonia Among Under-Five Children in Ethiopia: A Systematic Review and Meta-Analysis
}

Yoseph Merkeb ( $\nabla$ ymerkeb11@gmail.com )

Debre Markos University

\section{Fentahun Adane}

Debre Markos University

\section{Research article}

Keywords: Ethiopia, Magnitude, Predictors, Under-five pneumonia

Posted Date: January 17th, 2020

DOI: https://doi.org/10.21203/rs.2.21129/v1

License: (c) (i) This work is licensed under a Creative Commons Attribution 4.0 International License.

Read Full License 


\section{Abstract}

Background Currently, Pneumonia is the leading cause of morbidity and mortality among under-five children in developing countries including Ethiopia. Despite, these problems are easily preventable and treatable it contributes to more than $18 \%$ of deaths of under-five children every year in Ethiopia. Regardless of these facts, there is a paucity of information regarding the magnitude and its predictors of pneumonia in Ethiopia. Thus, assessing the pooled magnitude of pneumonia and its predictors among under-five children in Ethiopia is the main objective of this review.

Methods The international databases such as MEDLINE/PubMed, EMBASE, Google Scholar, Science Direct were scientifically explored. We considered all primary studies reporting the magnitude of pneumonia among under-five children and its predictors in Ethiopia. We retrieved all necessary data by using a standardized data extraction format spreadsheet. STATA 14 statistical software was used to analyze the data and Cochrane $\mathrm{Q}$ test statistics and I 2 test was used to assess the heterogeneity between the studies. There was significant heterogeneity between the studies so that a random effect model was employed.

Result The pooled magnitude of Pneumonia Among Under Five Children was 20.68\%, (I $2=97.9 \% \%$; $\mathrm{P} \leq$ 0.001 ) from 12 included studies in Ethiopia. Children who unvaccinated [OR $=2.45$ ], food cooking in the main house [OR $=2.46$ ], Vitamin A supplementation status [OR $=2.85$ ], malnutrition [OR $=2.98$ ], mixed breast feeding [OR $=2.46]$, child history of respiratory tract infection [OR $=4.11$ ] were a potential determinates of pneumonia.

Conclusion and Recommendations This review showed that the magnitude of pneumonia was relatively high. Hence, appropriate intervention on potential determinates such as health education on exclusive breastfeeding and nutrition, place of food cooking, increase immunization and Vitamin A supplementation and early control of respiratory tract infection was recommended to prevent those risk factors.

\section{Background}

Pneumonia is defined as an acute infection of the lung parenchyma, which can be caused by many pathogens like viruses, bacteria and fungi $[1,2]$. Pneumonia is the leading cause of morbidity and mortality among under-five children [3]. In 2016, Pneumonia accounting for approximately $16 \%$ of the 5.6 million under-five deaths, killing around 900,000 children worldwide [4]. In the same year, according to the WHO report, pneumonia accounted for approximately $16 \%$ of the estimated 5.9 million deaths among children aged less than 5 years $[5,6]$. Worldwide, the incidence of pneumonia in the under-five age group is estimated to be 0.29 and 0.05 episodes per child-year in developing and developed countries respectively, of all cases about $7-13 \%$ is life-threatening and require hospitalization [7]. Sub-Saharan Africa bears the highest (50\%) burden of the global under-five mortality rate of pneumonia [8]. In 2016, approximately 490,000 children under-five died by pneumonia in sub-Saharan Africa [9]. Ethiopia is one 
of the SSA countries with the highest magnitude of pneumonia, with estimated 3,370,000 children encounter pneumonia annually which contributes to $18 \%$ of all causes of deaths more than 40,000 underfive children every year [5].

Even though, these deaths are easily treatable and preventable by cost-effective interventions like immunization, good nutrition, exclusive breastfeeding, zinc and vitamin A supplementation appropriate complementary feeding, safe drinking water and good sanitation and control of environmental factors, but due to delays in recognizing pneumonia contribute to the highest the death of under-five children in every year $[10,11]$. Despite the Ethiopian government has adopted and implemented different strategies to reduce pneumonia morbidity and mortalities, burden and severity of childhood pneumonia is high and continue to common mortality of children due to due to limited coverage and affordability of effective preventive interventions like immunization, and lack of good access to care and unavailability of effective management strategies which calls for innovative strategies that will come about only through systematic researches $[12,13]$. Although the magnitude of pneumonia among under-five children in Ethiopia has improved due to different interventions, it remains the major cause of death among underfive children.

In Ethiopia, contradicted and inconsistency studies have been conducted to assess the magnitude and predictors of pneumonia among under-five children. The impact is still higher and with abundant discrepancy and inconstancy across regions related to assessing the magnitude and predictors of pneumonia. Data on the magnitude of pneumonia and their related risk factors are important for planning child health care services but scarce in Ethiopia. Regardless of these facts, in Ethiopia, there is a paucity of information regarding the magnitude and predictors of pneumonia. Thus, assessing the pooled magnitude of pneumonia and its predictors at a country level is essential and will provide an overall figure with better estimation. Therefore, the main objective of this systematic review and metaanalysis was to estimate the pooled magnitude of pneumonia and its predictors in Ethiopia. Findings obtained from this review will contribute to evidence for policymakers and program planners who working at various levels on the area to inform, plan, implement and evaluate health promotion policies and strategies. The study also will provide baseline information for researchers.

\section{Materials And Methods}

\section{Searching strategies and Study design}

This review was considered to evaluate the combined magnitude and predictors of pneumonia among under-five children in Ethiopia. In this review, we searched databases without limit to the date of publication and study design. To confirm the scientific accuracy, the Preferred Reporting Items of Systematic Reviews and Meta-Analysis Protocol (PRISMA-P) guideline was used [14]. The international databases include MEDLINE/PubMed, EMBASE, Web of Sciences, Scopus, and Grey literature databases, Google Scholar, Science Direct and Cochrane library were scientifically explored. Also, we assessed

reference lists of the articles found through the database search to retrieve additional articles and 
included the articles relevant to our topic of review. Unpublished studies were retrieved from the official websites of international and local organizations and universities. The search was performed by keywords, medical subject headings (MeSH) terms. We used the search terms independently and/or in combination using "OR", "AND" or "NOT". Keywords/search terms were "magnitude" OR "Epidemiology" AND "Children" AND/OR "Under Five Children" AND/OR "Childhood" AND/OR "factors" AND/OR "associated factors" AND/OR "risk factors" AND/OR "determinants" AND/OR "predictors" AND" Ethiopia". All articles conducted from September 30, 2019, up to November 30, 2019, and all accessible studies up to November 30,2019 , were incorporated in our meta-analysis and systematic review.

\section{Study Identification, Selection and Eligibility Criteria}

This meta-analysis and systematic review included the primary studies that assessed the magnitude of pneumonia and predictors among under-five children in Ethiopia.

\section{Inclusion criteria}

The magnitude and associated risk factors of pneumonia among under-five children in Ethiopia

Study area: Only articles conducted in Ethiopia.

Study design: All observational studies (cross-sectional, case controls, and cohort) that contain original data reporting the prevalence and associated risk factors of pneumonia among under-five children in Ethiopia were considered.

Language: It included literature published in English.

Population: Studies carried out in Ethiopia among children under five were considered.

Publication condition: A consideration was extended to both published articles and unpublished work in English.

Exclusion criteria: Research that was unpublished, irretrievable from the internet or failed to receive email replies from the corresponding authors was excluded. Furthermore, research which did not report our results of interest was excluded after a complete review of the texts

\section{Outcome of interest}

The main result of this study was to estimate the pooled magnitude and identify pneumonia predictors among children under five in Ethiopia.

\section{Data extraction and synthesis}

Data were retrieved by two independent reviewers (YM and FA) by using a standardized data extraction spreadsheet format. The data abstraction format includes the author, the study year, region of study setting (region and rural or urban), study design, sample size, magnitude, and predictor variables. Any 
disagreements during the extraction process were solved by consensus between the reviewers. If we got incomplete data, we excluded the study after two attempts were made to contact the corresponding author by email. Also, the two authors (YM and FA) performed the quality assessment of studies independently. Any discrepancy was resolved by discussion and agreement.

\section{Quality Assessment (appraisal) of the individual studies}

Duplicate articles were removed manually using Endnote (version X8) after combining the Database search results. To assess the quality of each study, Joanna Briggs Institute Meta-Analysis of Statistics Assessment and Review Instrument (JBI-MAStARI) adapted for both cross-sectional and case-control study design was used [15]. The original study was assessed by two reviewers independently and any disagreement between the reviewers was solved by taking the mean score of the two reviewers. Finally, the original studies which score five and above were included in the final review.

\section{Statistical methods and analysis}

For farther analysis, we imported the data to STATA version 14.0 statistical software after extracting the data using Microsoft Excel format.

Using the binomial distribution formula, Standard error was calculated for each study. The overall pooled magnitude of pneumonia among under-five children in Ethiopia was calculated using the standard error (SE) from each study. The pooled magnitude of pneumonia with $95 \% \mathrm{Cl}$ was presented using forest plots and Odds ratio (OR) with $95 \% \mathrm{Cl}$ was also presented in forest plot to show the predictors with pneumonia. We identify the heterogeneity between the studies using Cochrane's Q statistics (Chi-square), inverse variance $\left(1^{2}\right)$ and $p$-values [16]. Heterogeneity or variation across studies was assessed using the inverse variance $\left(I^{2}\right)$ with Cochran Q statistic at $25 \%, 50 \%$ and $75 \%$ was used to declare as low, moderate and high heterogeneity respectively [17]. The statistical output showed that there was significant heterogeneity among the studies $\left(I^{2}=97.9 \%, P \leq 0.001\right)$ so that we used a random-effects meta-analysis model to estimate the pooled magnitude and predictors of pneumonia among under-five children in Ethiopia. Also, we used a forest plot to detect the presence of heterogeneity. Furthermore, subgroup analysis was conducted by region of the study, study period and sample size, and meta-regression were used to identify the possible source of heterogeneity. The evidence of publication bias was checked using funnel plot symmetry. Besides, the statistical significance of publication bias was assessed using both Egger's and Beggar's test, subsequently, a trim-and-fill analysis was performed, with the $p$-value, less than $5 \%$ was used to declare the presence of publication bias $[18,19]$.

\section{Results}

\section{Selection of studies}

A total of 426 studies were identified using electronic searches (through Database searching $(n=422)$ ) and other sources $(n=4))$ that were conducted from 2014 up to 2019. Of these, 98 studies were excluded 
due to duplication. From the remaining 328 studies, after reviewing the title and abstract 312 studies were excluded as they were irrelevant for this systematic review and meta-analysis. The remaining 16 full-text articles were assessed for eligibility criteria based on the pre-defined criteria. Among these four articles were further excluded due to they are not in line with the preset criteria. Finally, 12 studies were fulfilled the eligibility criteria and included in this systematic review and meta-analysis (Fig.1).

\section{Characteristics of the studies}

In this review, a total of twelve articles met the inclusion criteria. A total of 4598 Study participants included in his systematic review with an estimated sample size a range from 206 to 558 in SNNP [20, 21] in individual studies, and all the included studies were published between 2015 and 2019. Both crosssectional and case-control studies were included in the current review.

In this meta-analysis and systematic review, of the total 12 included studies, four studies were conducted from Amhara region[2, 22-24], four studies from Oromia region [25-28], two studies from SNNP [20, 21], two studies from Addis Ababa $[29,30]$ (Table 1).

\section{Meta-analysis}

\section{Magnitude of Pneumonia Among Under Five Children in Ethiopia}

The magnitude of Pneumonia Among Under Five Children in Ethiopia from included studies ranged between $4.1 \%$ to $39.6 \%[24,30]$. As indicated in the forest plot below, the pooled magnitude of Pneumonia Among Under Five Children from 12 studies in Ethiopia was 20.68\% (95\% Cl: 12.49, 28.88). We identified a high and significant heterogeneity between studies $\left(I^{2}=97.9 \% \% ; P \leq 0.001\right)$, indicating great variability in magnitude of pneumonia across studies, random effect analysis model was used to estimate the pooled magnitude of pneumonia among under-five children in Ethiopia (Fig. 2).

\section{Publication bias}

Publication bias was observed using both Begg's and egger's test[18, 19], the value was found to be significant at a p-value of 0.004 and 0.020 respectively. These tests showed that there was statistical evidence of publication bias at a p-value less than 0.05 and the funnel plot was asymmetry. By considering publication bias trim and fill meta-analysis [31 was done to account for the publication bias. However, based on this analysis, the prevalence of pneumonia among under-five children was 20.68 and no significant change was showed as compared with the main meta-analysis.

\section{Sensitivity and Subgroup analysis}

Due to considerable heterogeneity in this review, Subgroup analysis was done to identify the source of heterogeneity based on the region and sample size. Subgroup analysis by region reports the pooled prevalence of pneumonia among under-five children was higher in the Amhara region $(27.80 \%)$ followed by Oromia region (22.65\%). Subgroup analysis was also carried out based on the sample size, according 
to this analysis the prevalence rate of $24.72 \%$ and $4.79 \%$ were revealed from Sample Size $<384$ and Sample Size $\geq 384$ respectively (Table 2 ). A sensitivity analysis was done to identify outlier studies. According to the analysis, no influential studies were detected so that all of the studies were included in the final analysis (Table 2).

\section{Meta-regression}

Besides subgroup analysis and publication bias, univariate and categorical meta-regression analysis was performed undertaken by considering both continuous and categorical data for the included studies to identify sources of for heterogeneity for the pooled prevalence. In meta-regression analysis, Sample size, publication year and study regions were considered for each study. However, there was no statistical significance value from the meta-regression analysis. Hence, the pooled prevalence of pneumonia among under-five children was not associated with sample size, publication year and study region (Table 3).

\section{Predictors of pneumonia among under-five children}

In this review, a total of 12 studies were included for analysis of predictors of pneumonia among underfive children. We identified six main associated factors with the pooled odds ratio ranging from 2.45 to 4.11. These predictors were Vaccination, Place of food cooking, VitA Supplementations, nutritional status, Exclusive breastfeeding, and respiratory tract infection. Unvaccinated children were 2.45 times more likely to have pneumonia as compared to children who fully vaccinated [OR $=2.45 ; 95 \% \mathrm{Cl}(1.13,5.31)]$. This result showed that children from the household who used the main house for a place of cooking were 2.46 times more likely to develop pneumonia as compared to those from household cook food in the kitchen $[\mathrm{OR}=2.46 ; 95 \% \mathrm{Cl}(1.66,3.66)]$. Children who were not ever supplemented with Vitamin A were 2.85 times more likely to develop pneumonia as compared to children who got Vitamin A supplementation $[\mathrm{OR}=2.85 ; 95 \% \mathrm{Cl}(1.36,5.56)]$. This review revealed that children who had MUAC less than $11.5 \mathrm{~cm}$ were 2.98 times more likely to develop pneumonia than children who had MUAC greater than or equal to $11.5[\mathrm{OR}=2.98 ; 95 \% \mathrm{Cl}(1.84,4.84)]$. Besides, the odds of pneumonia among under-five children who had not got exclusive breastfeeding were 2.46 times higher risk to develop pneumonia as compared to children who had got exclusive breastfeeding during the first six 6 months [OR $=2.46 ; 95 \%$ $\mathrm{Cl}(1.35,4.47)]$. According to this review, Children who had a history of respiratory tract infection were 4.11 times more likely to develop pneumonia compared to those who had no respiratory tract infection [OR $=4.11 ; 95 \% \mathrm{Cl}(1.98,8.52)]$ (Table 4).

\section{Discussion}

Currently, pneumonia among under-five children is a driving cause of morbidity and mortality in middle and low-income countries including Ethiopia. Assessing prevalence and its risk factors of pneumonia are essential for proper planning of child health care services, for proper management and prevention strategy. In this meta-analysis, we systematically reviewed studies assessing pneumonia and associated factors among under-five children in Ethiopia. As far as our knowledge, there is no previous review of the issue. Thus, this systematic review and meta-analysis aimed to estimate the pooled prevalence of 
pneumonia and its predictors in Ethiopia. The pooled Prevalence of Pneumonia Among Under Five Children from 12 included studies in Ethiopia was 20.68\% (95\% Cl: 12.49, 28.88), $\left(\mathrm{I}^{2}=97.9 \% \% ; \mathrm{P} \leq 0.001\right)$. This finding is lower than another studies done in Austria (4.1\%) [31], in Mali (6.7\%) [32], in Kenya (6.9\%) [33]. In contrast to this, our finding is higher than the studies done in Bangladesh (21.3\% ) [34], in Nigeria (31.6\%) [35] , in Uganda (53.7\% ) [36]. This discrepancy may be due to socio-economic and sociodemographic vitiations, the difference in the study setting, seasonal variation, inaccessibility and provision of Vitamin A supplementation and immunization, lack of confirmatory laboratories and imaging investigations. This review showed that children from the household who used charcoal and main house for a place of cooking were more than two times more likely to develop pneumonia than those who did not use it. This finding was supported by other studies $[22,37,38]$. The possible explanations could be high indoor air pollution may adversely affect host defenses of the respiratory tract against pathogens. This finding also supported by the UNICEF report confirmed that exposing children to household air pollution like solid fuels during cooking food in the main house double their risk of pneumonia [39]. Children who were not ever supplemented with Vitamin A were almost three times more likely to develop pneumonia as compared to children who got Vitamin A supplementation. This finding is in agreement with that of a study done in Rwanda [40]. This may due to the fact that the role of vitamin A is essential in the growth and development of respiratory epithelial cells and lung tissue [41]. Our study finding indicated that unvaccinated children were 2.45 times more vulnerable to develop pneumonia as compared to children who fully vaccinated which were supported by the study undertaken in India [42]. This could be justified that vaccinations and immunizations prevent children from developing infections that can lead to pneumonia as a complication [43]. Also, the odds of pneumonia among under-five children who had not got exclusive breastfeeding were 2.46 times higher risk to develop pneumonia as compared to children who had got exclusive breastfeeding during the first six 6 months. This result is in agreement with the UNICEF report [39]. This review revealed that children who had MUAC less than 11.5 $\mathrm{cm}$ were three times more likely to develop pneumonia than children who had MUAC greater than or equal to 11.5. It supported by a study conducted in India [44]. This might have explained that undernutrition which weakens the child's overall immune system and undernourished children have weakened respiratory muscles, which inhibits them from adequately clearing secretions found in their respiratory tract makes the child vulnerable to pneumonia [39]. According to this review, Children who had a history of respiratory tract infection were 4.11 times more likely to develop pneumonia compared to those who had no respiratory tract infection which was supported by the studies done in Kenya and Netherlands[45, 46].

\section{Strengths and limitations}

Primarily, this systematic review and meta-analysis used internationally accepted tools for a critical appraisal system for quality assessment of individual studies. It included both published and unpublished articles.

\section{Conclusion And Recommendation}


This review showed that the prevalence rate of pneumonia was relatively high in Ethiopia compared to other studies' reports from developing countries. Vitamin A supplementation, vaccination status, malnutrition, history of child respiratory tract infection, place of food cooking and breastfeeding status during 6 months were independent potential predictors of under-five pneumonia. Hence, appropriate intervention on potential determinates such as health education on exclusive breastfeeding and nutrition, place of food cooking, increase immunization and Vitamin A supplementation and early control of respiratory tract infection was recommended to prevent those risk factors.

\section{Abbreviations}

Cl: Confidence Interval; OR: Odds Ratio; SSA: Sub-Saharan Africa; SNNP: South Nation Nationalities of People U5M: Under Five Mortalities; WHO: World Health Organization; YM: Yoseph Merkeb; Fentahun Adane; MUAC: Middle Upper Arm Circumference

\section{Declarations}

\section{Ethics approval and consent to participate}

Not applicable

\section{Consent for publication}

Not applicable

\section{Availability of data and material}

The datasets analyzed during the current study are available from the corresponding author upon reasonable request.

\section{Competing interests}

We have confirmed that we have no competing interests.

\section{Funding}

No funding was obtained for this study.

\section{Authors' contributions}

YM and FA: developed the study design and protocol, literature review, selection of studies, quality assessment, data extraction, statistical analysis, interpretation of the data and developing the initial drafts of the manuscript and prepared the final draft of the manuscript. Both authors read and approved the final manuscript 
Acknowledgments

we gratefully thank the primary authors of the included studies.

Authors information

${ }^{1}$ Department of Biomedical Sciences School of Medicine, Debre Markos University, Debre Markos, Ethiopia.

\section{References}

1. Kalil AC, Metersky ML, Klompas M, Muscedere J, Sweeney DA, Palmer LB, Napolitano LM, O'Grady NP, Bartlett JG, Carratalà J: Management of adults with hospital-acquired and ventilator-associated pneumonia: 2016 clinical practice guidelines by the Infectious Diseases Society of America and the American Thoracic Society. Clinical Infectious Diseases 2016, 63(5):e61-e111.

2. Markos Y, Dadi AF, Demisse AG, Ayanaw Habitu Y, Derseh BT, Debalkie G: Determinants of Under-Five Pneumonia at Gondar University Hospital, Northwest Ethiopia: An Unmatched Case-Control Study. Journal of environmental and public health 2019, 2019.

3. Black RE, Morris SS, Bryce J: Where and why are $\mathbf{1 0}$ million children dying every year? The lancet 2003, 361(9376):2226-2234.

4. Hogan DR, Stevens GA, Hosseinpoor AR, Boerma T: Monitoring universal health coverage within the Sustainable Development Goals: development and baseline data for an index of essential health services. The Lancet Global Health 2018, 6(2):e152-e168.

5. Pires SM, Fischer-Walker CL, Lanata CF, Devleesschauwer B, Hall AJ, Kirk MD, Duarte AS, Black RE, Angulo FJ: Aetiology-specific estimates of the global and regional incidence and mortality of diarrhoeal diseases commonly transmitted through food. PloS one 2015, 10(12):e0142927.

6. Requejo JH, Bryce J, Barros AJ, Berman P, Bhutta Z, Chopra M, Daelmans B, De Francisco A, Lawn J, Maliqi B: Countdown to 2015 and beyond: fulfilling the health agenda for women and children. The Lancet 2015, 385(9966):466-476.

7. Rudan I, Boschi-Pinto C, Biloglav Z, Mulholland K, Campbell H: Epidemiology and etiology of childhood pneumonia. Bulletin of the world health organization 2008, 86:408-416B.

8. Nair H, Simões EA, Rudan I, Gessner BD, Azziz-Baumgartner E, Zhang JSF, Feikin DR, Mackenzie GA, Moiïsi JC, Roca A: Global and regional burden of hospital admissions for severe acute lower respiratory infections in young children in 2010: a systematic analysis. The Lancet 2013, 381(9875):1380-1390.

9. UNICEF: A Fair Chance for Every Child: The State of the World's Children 2016. In.: New York: UNICEF; 2016.

10. Young M, Wolfheim C, Marsh DR, Hammamy D: World Health Organization/United Nations Children's Fund joint statement on integrated community case management: an equity-focused strategy to 
improve access to essential treatment services for children. The American journal of tropical medicine and hygiene 2012, 87(5_Suppl):6-10.

11. Chopra M, Mason E, Borrazzo J, Campbell H, Rudan I, Liu L, Black RE, Bhutta ZA: Ending of preventable deaths from pneumonia and diarrhoea: an achievable goal. The Lancet 2013, 381(9876):1499-1506.

12. Zar H: Childhood pneumonia-looking beyond mortality. African J Resp Med 2016, 11(2):12-14.

13. UNICEF W: Pneumonia and diarrhoea: Tackling the deadliest diseases for the world's poorest children. New York: UNICEF 2012, 2013.

14. Moher D, Liberati A, Tetzlaff J, Altman DG: Preferred reporting items for systematic reviews and meta-analyses: the PRISMA statement. Annals of internal medicine 2009, 151(4):264-269.

15. Institute Jonna Briggs: Meta-Analysis of Statistics: Assessment and Review Instrument (JBI Mastari). Adelaide: Joanna Briggs Institute. 2006:20032.

16. Higgins JP, Thompson SG, Deeks JJ, Altman DG: Measuring inconsistency in meta-analyses. $B M J$ : British Medical Journal 2003, 327(7414):557.

17. Higgins Julian PT, Thompson Simon G, and Deeks Jonathan $\mathrm{J}$ et al: Measuring inconsistency in meta-analyses. BMJ: British Medical Journal 2003, 327(7414):557.

18. Begg CB, Mazumdar M: Operating characteristics of a rank correlation test for publication bias. Biometrics 1994:1088-1101.

19. Egger M, Smith GD, Schneider M, Minder C: Bias in meta-analysis detected by a simple, graphical test. Bmj 1997, 315(7109):629-634.

20. Abuka T: Prevalence of pneumonia and factors associated among children 2-59 months old in Wondo Genet district, Sidama zone, SNNPR, Ethiopia. Current Pediatric Research 2017.

21. Workineh Y, Hailu D, Gultie T: Determinants of pneumonia among under two children in southern Ethiopia: A case control study 2016. Current Pediatric Research 2017, 21(4).

22. Fekadu GA, Terefe MW, Alemie GA: Prevalence of pneumonia among under-five children in Este Town and the surrounding rural Kebeles, Northwest Ethiopia: a community based cross sectional study. Science Journal of Public Health 2014, 2(3):150-155.

23. Dadi AF, Kebede $Y$, Birhanu Z: Determinants of pneumonia in children aged two months to five years in urban areas of Oromia Zone, Amhara Region, Ethiopia. Open Access Library Journal 2014, 1(08):1.

24. GIZACHEW N: MAGNITUDE OF PNEUMONIA AND ASSOCIATED FACTORS AMONG UNDER FIVE CHILDREN IN DEBRE BERHAN REFERRAL HOSPITAL, NORTH SHOA, ETHIOPIA. 2019.

25. Lema B, Seyoum K, Atlaw D: Prevalence of Community Acquired Pneumonia among Children 2 to 59 Months Old and its Associated Factors in Munesa District, Arsi Zone, Oromia Region, Ethiopia. Clinics Mother Child Health 2019, 16:334.

26. Deribew A, Tessema F, Girma B: Determinants of under-five mortality in Gilgel gibe field research center, Southwest Ethiopia. Ethiopian Journal of Health Development 2007, 21(2):117-124. 
27. Lema K, Murugan R, Tachbele E: Prevalence and associated factors of pneumonia among under-five children at public hospitals in Jimma zone, South West of Ethiopia, 2018. J Pulmonol Clin Res 2018; 2 (1): 25-31 J Pulmonol Clin Res 2018 Volume 2 Issue, 1.

28. Geleta D, Tessema F, Ewnetu H: Determinants of Community Acquired Pneumonia among Children in Kersa District, Southwest Ethiopia: Facility Based Case Control Study. Journal of Pediatrics and Neonatal Care 2016, 5(2):00179.

29. Negash AA, Asrat D, Abebe W, Hailemariam T, Hailu T, Aseffa A, Vaneechoutte M: Bacteremic community-acquired pneumonia in Ethiopian children: etiology, antibiotic resistance, risk factors, and clinical outcome. In: Open forum infectious diseases: 2019: Oxford University Press US; 2019: ofz029.

30. Jofiro G, Jemal K, Beza L, Heye TB: Prevalence and associated factors of pediatric emergency mortality at Tikur Anbessa specialized tertiary hospital: a 5 year retrospective case review study. BMC pediatrics 2018, 18(1):316.

31. Kurz H, Göpfrich H, Huber K, Krugluger W, Asbott F, Wabnegger L, Apfalter P, Sebesta C: Spectrum of pathogens of in-patient children and youths with community acquired pneumonia: a 3 year survey of a community hospital in Vienna, Austria. Wiener klinische Wochenschrift 2013, 125(21-22):674-679.

32. Bénet T, Sylla M, Messaoudi M, Picot VS, Telles J-N, Diakite A-A, Komurian-Pradel F, Endtz H, Diallo S, Paranhos-Baccalà G: Etiology and factors associated with pneumonia in children under 5 years of age in Mali: a prospective case-control study. PloS one 2015, 10(12):e0145447.

33. Hammitt LL, Kazungu S, Morpeth SC, Gibson DG, Mvera B, Brent AJ, Mwarumba S, Onyango CO, Bett A, Akech DO: A preliminary study of pneumonia etiology among hospitalized children in Kenya. Clinical infectious diseases 2012, 54(suppl_2):S190-S199.

34. Azad KMAK: Risk factors for acute respiratory infections (ARI) among under-five children in Bangladesh. Journal of Scientific Research 2009, 1(1):72-81.

35. Ujunwa F, Ezeonu C: Risk Factors for Acute Respiratory Tract Infections in Under-five Children in Enugu Southeast Nigeria. Annals of medical and health sciences research 2014, 4(1):95-99.

36. Ndeezi G, Tumwine J: Asthma and pneumonia among under-fives at Mulago National Referral Hospital Uganda: Is asthma under diagnosed. In: 8th European Congress on Tropical Medicine and International Health: a hospital based cross sectional survey University of Copenhagen: 2013; 2013.

37. Uddin K, Jahan N, Manan M, Ferdousi S, Farhana T, Akhter S, Alam R: Risk factors determining the outcome of 2-12 months age group infants hospitalized with severe pneumonia. Medicine Today 2013, 25(1):9-13.

38. Sharma SR, Bhandari NN, Bhandari R, Wagle K, Adhikari M: Types of cooking stove and risk of Acute Lower Respiratory Infection among under-five children: a cross sectional study in Rasuwa, a Himalayan district of Nepal. Health Prospect 2015, 14(1):1-7.

39. Wardlaw TM, Johansson EW, Hodge MJ: Pneumonia: the forgotten killer of children: Unicef; 2006.

40. Cancedda C, Cotton P, Shema J, Rulisa S, Riviello R, Adams LV, Farmer PE, Kagwiza JN, Kyamanywa $P$, Mukamana D: Health professional training and capacity strengthening through international 
academic partnerships: The first five years of the Human Resources for Health Program in Rwanda. International journal of health policy and management 2018, 7(11):1024.

41. Ramezani M, Aemmi SZ, Emami Moghadam Z: Factors affecting the rate of pediatric pneumonia in developing countries: a review and literature study. International Journal of Pediatrics 2015, 3(6.2):1173-1181.

42. Nirmolia N, Mahanta TG, Boruah M, Rasaily R, Kotoky RP, Bora R: Prevalence and risk factors of pneumonia in under five children living in slums of Dibrugarh town. Clinical Epidemiology and Global Health 2018, 6(1):1-4.

43. Tong N: Background Paper 6.22 Pneumonia. A Public Health Approach to Innovation,"(May) 2013:78.

44. Srivastava P, Mishra A, Roy A: Predisposing factors of community acquired pneumonia in under-five children. Journal of Lung Diseases \& Treatment 2015, 1(1):2472-1018.1000101.

45. Onyango D, Kikuvi G, Amukoye E, Omolo J: Risk factors of severe pneumonia among children aged 259 months in western Kenya: a case control study. Pan African Medical Journal 2012, 13(1).

46. Teepe J, Grigoryan L, Verheij T: Determinants of community-acquired pneumonia in children and young adults in primary care. European Respiratory Journal 2010, 35(5):1113-1117.

\section{Tables}

Table 1: Characteristics of 12 studies reporting the prevalence of pneumonia and its predictors among under-five children in Ethiopia from 2014 up to 2019. 


\begin{tabular}{|c|c|c|c|c|c|c|c|}
\hline SN & Author & $\begin{array}{l}\text { Publication } \\
\text { Year }\end{array}$ & Region & Study area & Study design & $\begin{array}{l}\text { Sample } \\
\text { size }\end{array}$ & $\begin{array}{l}\text { Quality } \\
\text { Score }\end{array}$ \\
\hline 1 & Negash et al & 2019 & $\begin{array}{l}\text { Addis } \\
\text { Ababa }\end{array}$ & Addis Ababa & $\begin{array}{l}\text { Cross- } \\
\text { sectional }\end{array}$ & 549 & 7 \\
\hline 2 & Jofiro et al & 2018 & $\begin{array}{l}\text { Addis } \\
\text { Ababa }\end{array}$ & Addis Ababa & $\begin{array}{l}\text { Cross- } \\
\text { sectional }\end{array}$ & 499 & 8 \\
\hline 3 & Fekadu et al & 2014 & Amhara & Este town & $\begin{array}{l}\text { Cross- } \\
\text { sectional }\end{array}$ & 286 & 6 \\
\hline 4 & A. F. Dadi et al & 2014 & Amhara & Oromia Zone & Case-Control & 356 & 7 \\
\hline 5 & $\begin{array}{l}\text { GIZACHEW } \\
\text { NESIBU }\end{array}$ & 2019 & Amhara & $\begin{array}{l}\text { DEBRE } \\
\text { BERHAN }\end{array}$ & $\begin{array}{l}\text { Cross- } \\
\text { sectional }\end{array}$ & 341 & 6 \\
\hline 6 & $\begin{array}{l}\text { Yordanos Markos } \\
\text { et al }\end{array}$ & 2019 & Amhara & Gondar & Case-Control & 435 & 7 \\
\hline 7 & Atlaw D, et al. & 2019 & Oromia & Arsi Zone & $\begin{array}{l}\text { Cross- } \\
\text { sectional }\end{array}$ & 344 & 8 \\
\hline 8 & A. Deribew et al & 2007 & Oromia & Gilgel Gibe & case-control & 336 & 7 \\
\hline 9 & Lema et al & 2018 & Oromia & Jimma zone & $\begin{array}{l}\text { Cross- } \\
\text { sectional }\end{array}$ & 306 & 8 \\
\hline 10 & Geleta et al & 2016 & Oromia & Kersa & case-control & 382 & 7 \\
\hline 11 & Workineh et al & 2017 & SNNP & $\begin{array}{l}\text { Gamo Gofa } \\
\text { Zone }\end{array}$ & case-control & 558 & 5 \\
\hline 12 & Teshome Abuka & 2016 & SNNP & Sidama zone & $\begin{array}{l}\text { Cross- } \\
\text { sectional }\end{array}$ & 206 & 7 \\
\hline
\end{tabular}

Table 2: Subgroup Analysis Which Describes the Pooled Prevalence of pneumonia among under-five children in Ethiopia, 2019. 


\begin{tabular}{|c|c|c|c|c|c|c|c|}
\hline \multicolumn{2}{|c|}{;ubgroup } & \multirow{2}{*}{$\begin{array}{l}\text { Included } \\
\text { Studies } \\
5\end{array}$} & Prevalence $(95 \%$ CI) & \multirow{2}{*}{$\begin{array}{l}\text { Heterogeneity } \\
\text { statistics } \\
59.84\end{array}$} & \multirow{2}{*}{$\begin{array}{l}\text { P- } \\
\text { value } \\
0.000\end{array}$} & \multirow{2}{*}{$\begin{array}{l}\mathrm{I}^{2} \\
(\%) \\
93.3\end{array}$} & \multirow{2}{*}{$\begin{array}{l}\text { Tau- } \\
\text { squared } \\
75.4120\end{array}$} \\
\hline ;ample & $<384$ & & (16.829, & & & & \\
\hline \multirow[t]{3}{*}{;ize } & & & $32.602)$ & & & & \\
\hline & $\geq 384$ & 2 & $4.792(3.326,6.257)$ & 1.29 & 0.257 & 22.2 & 0.2496 \\
\hline & Addis & 2 & $4.792(3.326,6.257)$ & 1.29 & 0.257 & 22.2 & 0.2496 \\
\hline \multirow[t]{4}{*}{ Region } & Ababa & & & & & & \\
\hline & Amhara & 2 & $27.801(4.772,50.831)$ & 47.05 & 0.000 & 97.9 & 270.2563 \\
\hline & Oromia & 3 & $(16.817$ & 10.07 & 0.007 & 80.1 & 21.2225 \\
\hline & & & $28.475)$ & & & & \\
\hline
\end{tabular}

Table 3: univariate and categorical meta-regression for the included studies to identify the source of heterogeneity for the prevalence of pneumonia among under-five children in Ethiopia.

\begin{tabular}{llll}
\hline Variables & Characteristics & Coefficient & P-value \\
\hline Year & Publication & -.2216302 & 0.865 \\
Sample size & & -0.0856182 & 0.027 \\
& Amhara & Reference & Reference \\
Region & Addis Ababa & -22.83555 & 0.064 \\
& Oromia & -4.9355 & 0.584 \\
& SNNP & 5.815305 & 0.636 \\
\hline
\end{tabular}

Table 4: Identified associated factors of pneumonia among under-five children in Ethiopia, 2019 


\begin{tabular}{lll}
\hline No. & Variables & OR $(95 \%$ CI $)$ \\
\hline 1. & Children who unvaccinated & $2.45(1.13,5.31)$ \\
2. & food cooking in the main house & $2.46(1.66,3.66)$ \\
3. & Lack of Vitamin A supplementation & $2.85(1.36,5.56)$ \\
4. & malnutrition & $2.98(1.84,4.84)$ \\
5. & mixed breast feeding & $2.46(1.35,4.47)$ \\
6. & child history of respiratory tract infection & $4.11(1.98,8.52)$ \\
\hline
\end{tabular}

\section{Figures}

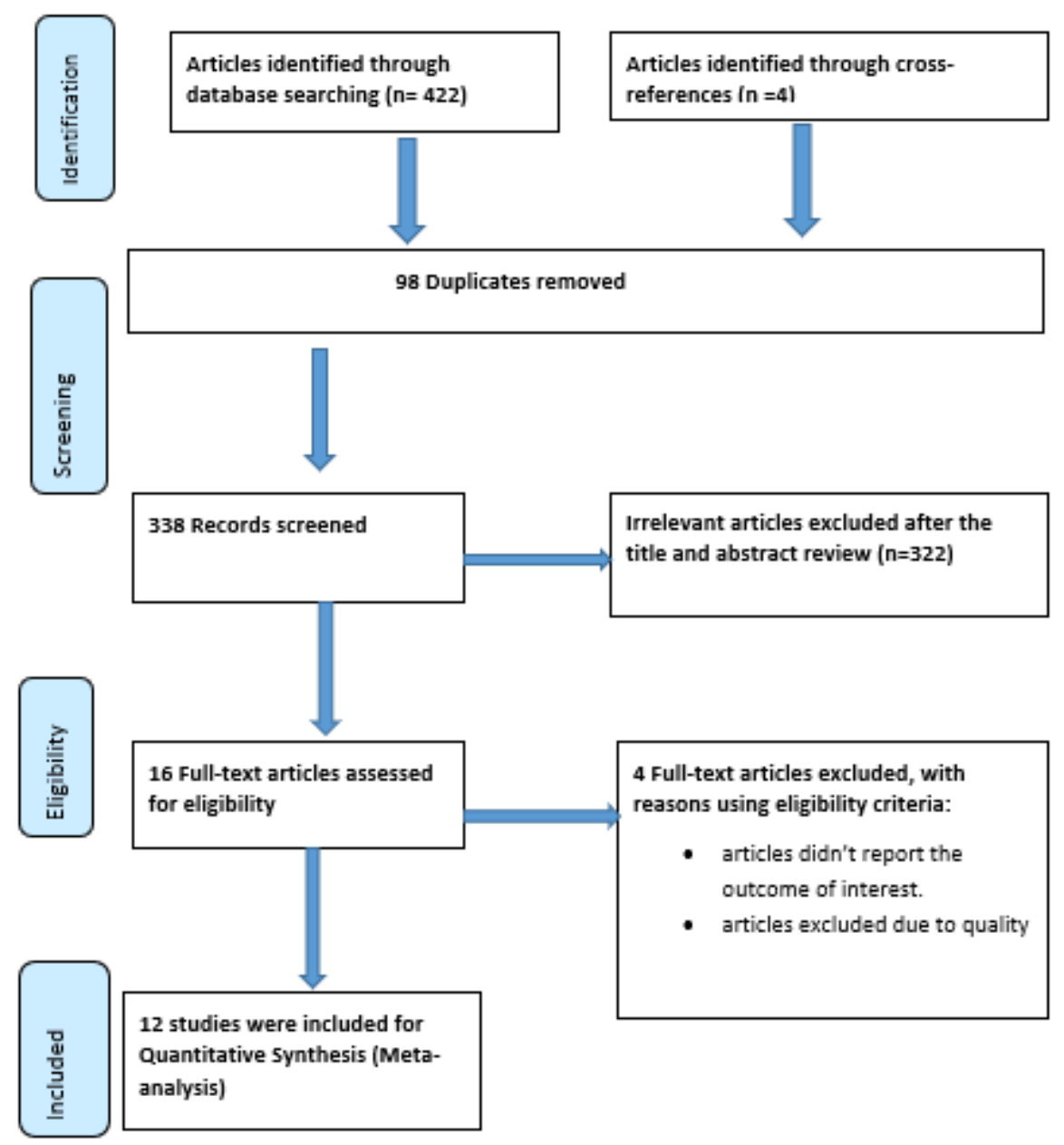

Figure 1

PRISMA flow diagram of included studies to estimate the pooled prevalence of pneumonia and its predictors among under-five children in Ethiopia from 2014 up to 2019. 


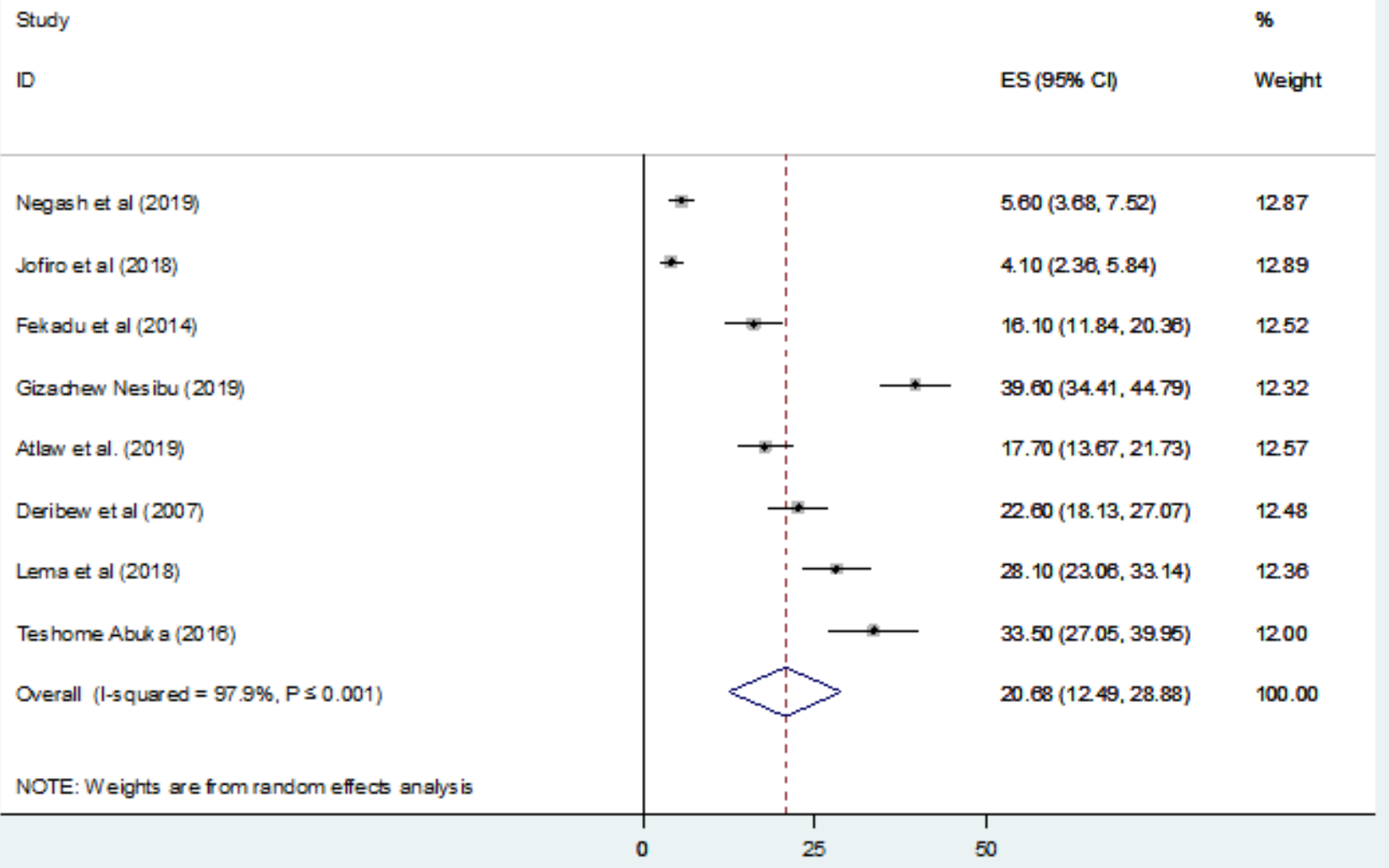

\section{Figure 2}

Forest plot showing the pooled prevalence of pneumonia among under-five children in Ethiopia from2014 up to 2019.

\section{Supplementary Files}

This is a list of supplementary files associated with this preprint. Click to download.

- PRISMA2009checklist.doc 